\title{
Design and Analysis of Suspension Strut in Automobile Vehicles
}

\author{
Anil Babu Seelam², Monish Senthil Kumaran ${ }^{1}$, Krishnamurthy H. Sachidananda ${ }^{2 *}$ \\ ${ }^{1}$ Manipal Academy of Higher Education, Dubai 345050, UAE \\ ${ }^{2}$ School of Engineering and IT, Manipal Academy of Higher Education, Dubai 345050, UAE
}

Corresponding Author Email: sachidananda@manipaldubai.com

https://doi.org/10.18280/mmep.070411

Received: 8 September 2020

Accepted: 12 November 2020

\section{Keywords:}

suspension strut, structural analysis, E-Glass, carbon fiber, structural steel

\begin{abstract}
This research paper discusses about the design and analysis of suspension strut used in automotive industries. The main objective of this research is to study the suspension strut by modelling using solid works and then analysis have been performed using ANSYS by considering structural steel, carbon fiber and E-Glass material. Based on the results obtained from the analysis, comparison have been made for above materials to reduce the weight of the suspension strut to improve the life of the model. From the analysis results it can be concluded that it is possible to reduce the weight of suspension strut using composite materials. From the above study it can be concluded that glass fiber has performed well as compared to other materials which in turn increases the life of the suspension strut.
\end{abstract}

\section{INTRODUCTION}

Suspension strut are a part of the car's suspension system that absorbs compression to reduce heavy bouncing and give smooth feeling while driving. Mercedes Benz strut assembly have been designed to stabilize the suspension system; Struts do this because they work like shock absorbers to stabilize the overall function of the suspension system. The struts work along with leaf springs, coil springs, and stabilizer bars to add increased tension and support to the suspension system. This can be achieved by evenly distributing vehicle body weight while the car is being driven. Most likely it consists of 4 struts, two in the rear and two in the front. These four struts work together to maintain a controlled ride. This helps to reduce the frame stress by absorbing the stress and impact while the car is being operated. Without the strut, the car ride would be extremely bumpy and there could be damage to the frame.

In this context some of the literature review has been performed and have been presented. Prakash et al. [1] have studied design and analysis of a coil spring of a strut assembly considering different materials using ANSYS. They used stainless steel and magnesium alloy for the strut spring to analyze its design for heavy loads by comparing deformation, stress etc. using ANSYS.

They concluded from their results it is possible to reduce the weight of the spring. Lavanya et al. [2] has studied suspension coil spring used in automotive vehicles. They investigated by comparing coil spring made of low-carbon structural steel and chrome vanadium steel. They concluded that strain and stress induced is less in case of low carbon structural steel as compared to chrome vanadium steel. Shinde et al. [3] has analyzed vibrations and noise of different components in case of McPherson suspension. They concluded by providing the gaps and how to improve its performance for safety. Dodamani et al. [4] have studied coil spring of a McPherson suspension system. They analyzed the coil springs using static and fatigue loading conditions and they concluded that there developed model is safe according to Von-misses and maximum stress. Alsahlani et al. [5] have studied coil springs using ANSYS. They studied deformation, strain, stress etc. considering various materials such as steel, copper alloy and carbon composites. They concluded that deformation in carbon composites is lesser as compared to other two materials considered. Vaidya et al. [6] have reviewed suspension systems for automobile applications. They discussed old suspension systems and the different advancement which has taken place in suspension systems. They concluded that suspension system is the backbone of automobile industries. Pawar et al. [7] have analyzed the front suspension coil spring for automobile vehicles. They studied theoretical analysis and compared the results with ANSYS analysis. They concluded that stiffness of the suspension increased which in turn increases load carrying capacity. Vijayeshwar et al. [8] have analyzed helical suspension springs considering different materials. They considered chrome silicon and hard drawn carbon steel material for the analysis and they concluded that chrome silicon has performed better as compared to hard drawn carbon steel. Pankaj et al. [9] have studied helical compression springs using ANSYS. They studied statistical structural analysis for the above spring considering chrome vanadium and cobalt chrome and they concluded that cobalt chrome has performed better as compared to other materials considered. Lukasz and Rafal [10] have studied suspension systems for automobile vehicles. They studied test method to evaluate technical conditions of modern suspension systems. They concluded that the diagnostic method used in assessment requires development and improvement. Purushotham [11] have studied a mathematical model of McPherson suspension system. He has studied the implementation of this model using Matlab-simulink and he concluded that displacement and acceleration were in line for theoretical as well as Matlabsimulink. Ali et al. [12] have studied suspension system for McPherson system. They studied the suspension system behavior during driving maneuvers. They concluded that using 
McPherson system it is possible to comfort ride apart from vehicle behavior. Jain et al. [13] have studied helical springs for suspension system. They studied stress and deflection in case of helical springs considering different materials. They concluded by comparing the results with ANSYS analysis. Yadav et al. [14] have studied helical springs of a suspension system. They studied using new materials to increase the stiffness of the springs. They concluded that Inconel X750 can be used and is best suitable for helical springs. Bhaskar et al. [15] have studied springs with fiber reinforced composite material. They studied deflection and spring rate for varying load conditions. They concluded that modification in cross section with proper material can increase the properties of composite springs. Krishnamoorthy and Karthik [16] have studied helical springs using glass fiber. They manufactured springs with glass fiber and resin, they concluded by studying the mechanical properties. Manjunatha and D Abdul Budan [17] have studied composite helical springs for automobile applications. They have studied mechanical behavior of the springs and they concluded that weight of the composite springs is lesser as compared to steel springs.

\section{METHODOLOGY}

This topic discusses about the methodology followed to design and analyze several composite materials for the selected suspension strut model. The software used for suspension strut design is the solid works and the software used for the analysis is ANSYS.

Formulas used for design:

$$
\begin{gathered}
\text { Load } \mathrm{F}=\mathrm{K} \Delta \\
\text { Deflection } \Delta=\frac{F}{K}=\frac{8 F D^{3} n_{a}}{G d^{4}} \\
n_{a}=n_{t}-n^{*}
\end{gathered}
$$

\subsection{Design of base rod for suspension strut}

The dimensions of the base rod used for suspension strut is as shown in Table 1 and Figure 1 shows the base rod for suspension strut.

Table 1. Design of base specifications

\begin{tabular}{cc}
\hline Nomenclature & Dimensions (mm) \\
\hline Circle diameter & 45 \\
Thickness & 3 \\
Top rod diameter $(\mathrm{mm})$ & 10 \\
Extrusion of top rod diameter & 70 \\
Lower rod diameter & 24 \\
Extrusion of lower rod diameter & 28 \\
Fillet radius & 6 \\
Hole diameter & 8 \\
\hline
\end{tabular}

Table 2. Nut specification

\begin{tabular}{cc}
\hline Nomenclature & Dimensions (mm) \\
\hline Outer Diameter & 52 \\
Inner diameter & 24 \\
Thickness & 10 \\
Extrusion of top rod diameter & 9 \\
Inner circle Extrusion & 29 \\
Circular pattern & 12 \\
Revolve cut angle & $15^{\circ}$ \\
\hline
\end{tabular}

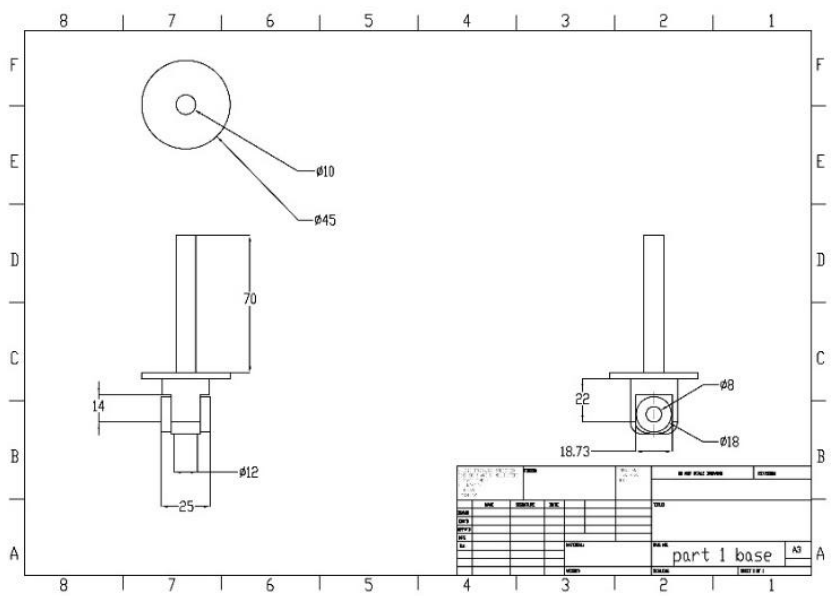

Figure 1. 2-D view of base rod for suspension strut

\subsection{Design of Nut}

The nut specification for the suspension strut is shown in Table 2 and the 2-D view of the nut is shown in Figure 2 and Figure 3.

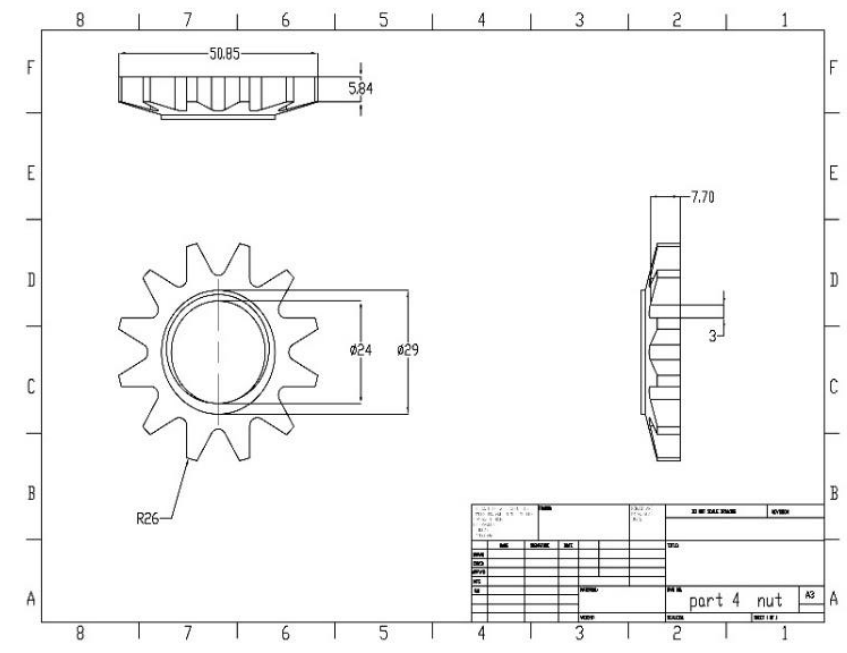

Figure 2. 2-D view of nut for suspension strut

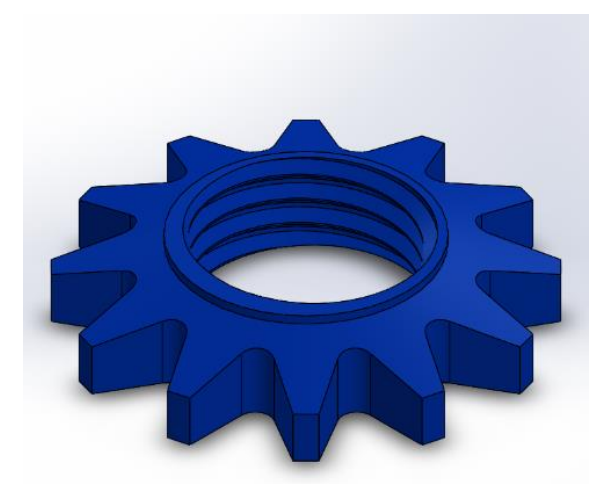

Figure 3. 3-D plane of nut for suspension strut

\subsection{Design of top rod}

The design specifications of the coil spring, 2-D view of the coil spring is as shown in Figure 4 and Table 3. The isometric view is as shown in Figure 5. 
Table 3. Top rod specification

\begin{tabular}{cc}
\hline Nomenclature & Dimensions (mm) \\
\hline Outer rod diameter & 28 \\
Lower rod diameter & 25 \\
Extrusion of lower rod diameter & 108 \\
Top edge fillet & 6 \\
Hole diameter & 8 \\
Thread height & 50 \\
Thread pitch & 3 \\
Boot fillet & 0.75 \\
Chamfer diameter & 4 \\
\hline
\end{tabular}

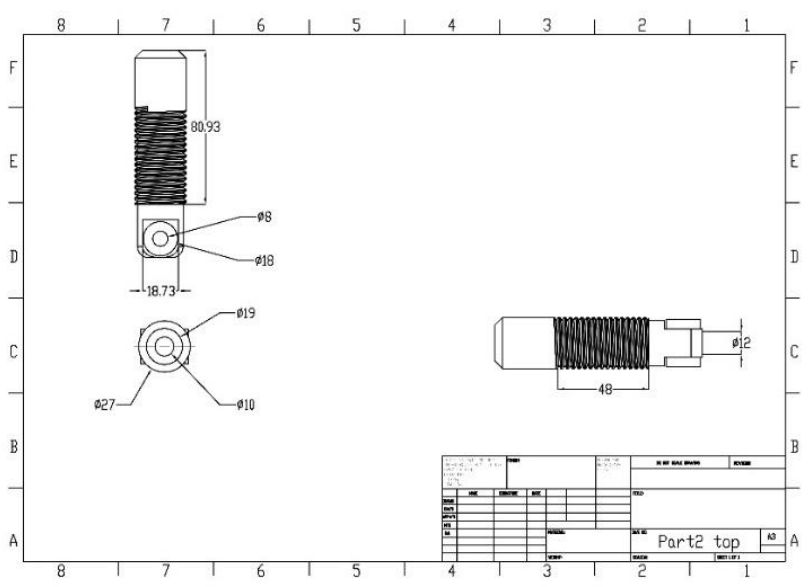

Figure 4. 2-D view of top rod for suspension strut

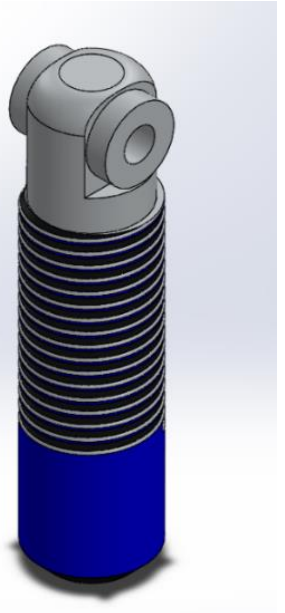

Figure 5. Isometric view of top rod for suspension strut

\subsection{Design of coil springs}

The design specifications of the coil spring, 2-D view of the coil spring, front plane, top plane and isometric view is as shown in Table 4, Figure 6 and Figure 7.

Table 4. Coil spring specifications

\begin{tabular}{cc}
\hline Nomenclature & Dimensions (mm) \\
\hline Diameter of spring wire & 7.25 \\
Pitch & 15 \\
Extrusion cut on top & 10 \\
Extrusion cut on bottom & 10 \\
Hole diameter & 8 \\
Number of coil springs & 6 \\
Free length of the spring & 99 \\
\hline
\end{tabular}

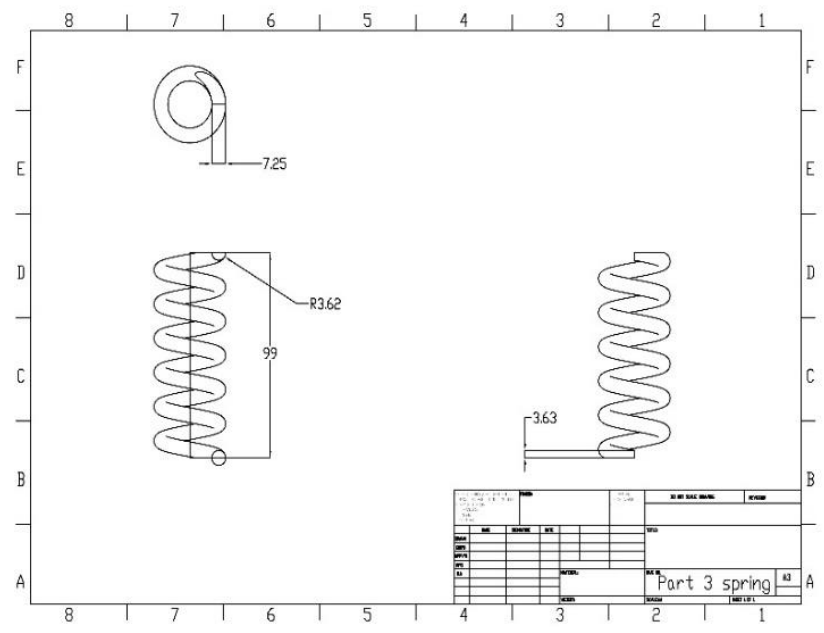

Figure 6. 2-D view of spring for suspension strut

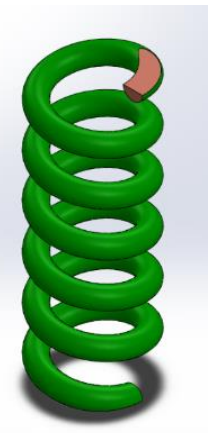

Figure 7. Isometric view of coil spring for suspension strut

\subsection{Assembly of suspension strut}

The design specifications of the suspension strut, 2-D view of the coil spring, front plane, top plane and isometric view is as shown in Table 5, Figure 8 and Figure 9.

Table 5. Assembly specifications

\begin{tabular}{cc}
\hline Mating features & Relations \\
\hline Coincident relation & Top rod and base rod \\
Concentric relation & Nut and top rod \\
Screw relation & Temporary axis and nut \\
Concentric relation & Nut and spring \\
Coincident relation & Spring and base \\
\hline
\end{tabular}

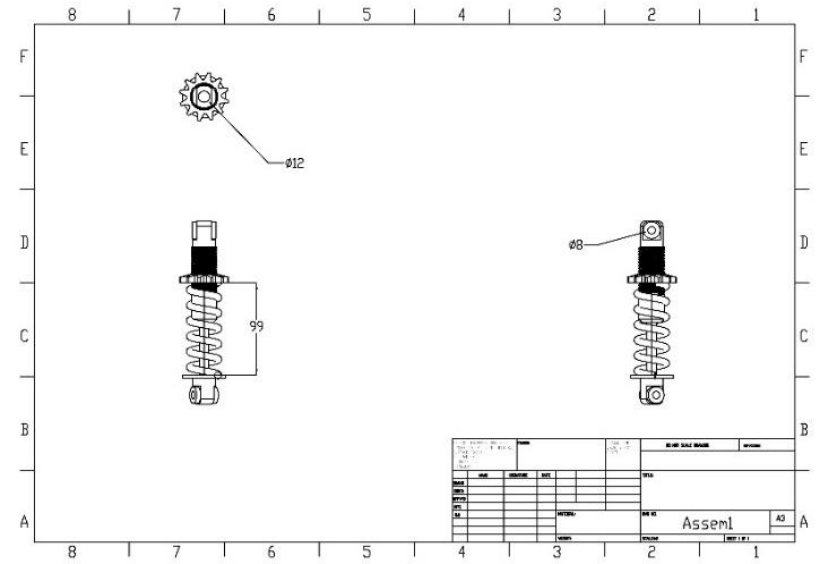

Figure 8. 2-D view assembly of suspension strut 


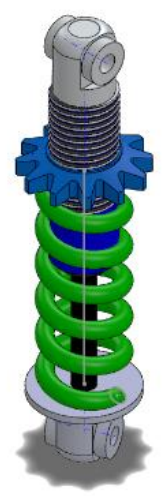

Figure 9. Isometric view of suspension strut

\subsection{Design calculations}

Deflection for structural steel coil spring is given as:

$$
\partial=\frac{8 W C^{3} n}{G d^{4}}=64.46 \mathrm{~mm}
$$

where, $\mathrm{W}$ is the load applied on the coil spring, which is 7500 $\mathrm{N}, \mathrm{C}=\mathrm{D} / \mathrm{d}=4.67 \mathrm{~mm}, \mathrm{n}$ is the number of active coils, $\mathrm{G}$ is the modulus of rigidity and $\partial$ is the deflection.

Similarly, deflection for the E-glass coil spring using the above formulae is $168.57 \mathrm{~mm}$ and the deflection for the carbon fiber coil spring is $339.4 \mathrm{~mm}$.

Weight of the C class model: $4000 \mathrm{~kg}$, Weight applied on one side of the vehicle: $4000 / 4=1000 \mathrm{~kg}=9800 \mathrm{~N}$ and approximating it to $10000 \mathrm{~N}=10 \mathrm{KN}$.

Considering $75 \%$ of the load to be added on the suspension strut from the original load. Therefore, load to be applied on suspension strut $=7500 \mathrm{~N}$.

Dynamic load exerted on the car

$\mathrm{F}=$ Mass $\mathrm{x}$ Acceleration

Mass of the car $=4000 \mathrm{~kg}$

Rate of Acceleration $=60 \mathrm{mph}=12.22$ feet-per-sec ${ }^{2}$

Therefore $\mathrm{F}=4000^{*} 0.3975=1590 \mathrm{kgs}$ is the dynamic load exerted by the drive-wheel tire treads against the road to accelerate the car.

\subsection{Structural steel}

The input values for the coil springs considering structural steel material is as shown in Table 6.

Table 6. Input values for structural steel

\begin{tabular}{cc}
\hline Nomenclature & Dimensions (mm) \\
\hline Diameter of spring wire, $\mathrm{d}$ & 7.25 \\
Outer diameter of spring, D & 30 \\
Free length of spring, L free & 99 \\
Number of active coils, $\mathrm{n}$ & 6 \\
Young's modulus of material & $200 \mathrm{GPa}$ \\
Poisson ratio of material & 0.3 \\
Density of material & $7850 \mathrm{Kg} / \mathrm{m} 3$ \\
\hline
\end{tabular}

The corresponding output values for the coil spring considering structural steel material is as follows.

- $\quad$ Maximum load possible $=1.54 * 104 \mathrm{~N}$

- $\quad$ Maximum shear stress $=3630 \mathrm{MPa}$

- Maximum displacement possible $=41 \mathrm{~mm}$

- $\quad$ Mass of spring $=0.188 \mathrm{~kg}$

\subsection{E-Glass}

The input values for the coil springs considering structural steel material is as shown in Table 7.

Table 7. Input values for E-Glass

\begin{tabular}{cc}
\hline Nomenclature & Dimensions $(\mathbf{m m})$ \\
\hline Diameter of spring wire, d & 7.25 \\
Outer diameter of spring, D & 30 \\
Free length of spring, L free & 99 \\
Number of active coils, $\mathrm{n}$ & 6 \\
Young's modulus of material & $85 \mathrm{GPa}$ \\
Poisson ratio of material & 0.22 \\
Density of material & $2600 \mathrm{Kg} / \mathrm{m} 3$ \\
\hline
\end{tabular}

The corresponding output values for the coil spring considering E-Glass material is as follows.

- $\quad$ Maximum shear stress $=1640 \mathrm{MPa}$

- $\quad$ Maximum displacement possible $=41 \mathrm{~mm}$

- $\quad$ Mass of spring $=0.0626 \mathrm{~kg}$

\subsection{Carbon fiber}

The input values for the carbon fiber considering structural steel material is as shown in Table 8 .

Table 8. Input values for E-Glass

\begin{tabular}{cc}
\hline Nomenclature & Dimensions (mm) \\
\hline Diameter of spring wire, d & 7.2 \\
Outer diameter of spring, D & 30 \\
Free length of spring, L free & 99 \\
Number of active coils, $\mathrm{n}$ & 6 \\
Young's modulus of material & $290 \mathrm{GPa}$ \\
Poisson ratio of material & 0.2 \\
Density of material & $1800 \mathrm{Kg} / \mathrm{m} 3$ \\
\hline
\end{tabular}

The corresponding Output value for carbon fiber coil springs:

- $\quad$ Maximum shear stress $=5690 \mathrm{Mpa}$

- Maximum displacement possible $=41 \mathrm{~mm}$

- Mass of spring $=0.0433 \mathrm{~kg}$

2.9.1 Selecting the load to be applied on the suspension strut

Weight of the $\mathrm{C}$ class model: $4000 \mathrm{~kg}$, Weight applied on one side of the vehicle: $4000 / 4=1000 \mathrm{~kg}=9800 \mathrm{~N}$ and approximating it to $10000 \mathrm{~N}=10 \mathrm{KN}$.

Considering $75 \%$ of the load to be added on the suspension strut from the original load. Therefore, load to be applied on suspension strut $=7500 \mathrm{~N}$.

\subsubsection{Weight reduction from structural steel}

The weight reduction is calculated using following formulae.

Weight Reduction $(\%)=\frac{W_{2}-W_{1}}{W_{1}}$.

\subsubsection{E- Glass}

Weight of E-Glass (W2) $=0.0626 \mathrm{Kg}$, Weight of Structural steel $(\mathrm{W} 1)=0.188 \mathrm{Kg}$, therefore weight reduction in case of E-Glass is $66.70 \%$ less than the structural steel.

\subsubsection{Carbon fiber}

Weight of carbon fiber $(\mathrm{W} 2)=0.0433 \mathrm{Kg}$, Weight of Structural steel $(\mathrm{W} 1)=0.188 \mathrm{Kg}$, therefore weight reduction 
in case of carbon fiber is $76.96 \%$ less than the structural steel.

From these results it can be analyzed the weight reduction in case of E-Glass is $66.70 \%$ whereas the weight reduction in case of carbon fiber is $76.96 \%$ as compared to structural steel. This weight reduction helps to increase the fuel consumption in the car. In case of carbon fiber, the weight reduction of $76.96 \%$ plays a major role in reducing the weight of the vehicle during design process.

\section{RESULTS AND DISCUSSIONS}

Structural analysis on the existing design using structural steel as a material have been performed using ANSYS and hence these values obtained are compared with carbon fiber and E-Glass material.

\subsection{Structural analysis for structural steel}

The upper surface of top rod is fixed support to the rocker arm and a load of $7500 \mathrm{~N}$ is applied between the holes of the base rod which is connected to the wheel hub and the boundary conditions applied is as shown in Figure 10. Fine mesh was used on the suspension strut ad the total nodes was 82284 and the number of elements in the analysis was 45058 and is as shown in Figure 11. The total deformation of the structural steel, stress, shear stress and elastic strain is as shown in Figure 12 to Figure 15. The corresponding values of total deformation, stress, shear stress and elastic strain is as shown in Table 9.

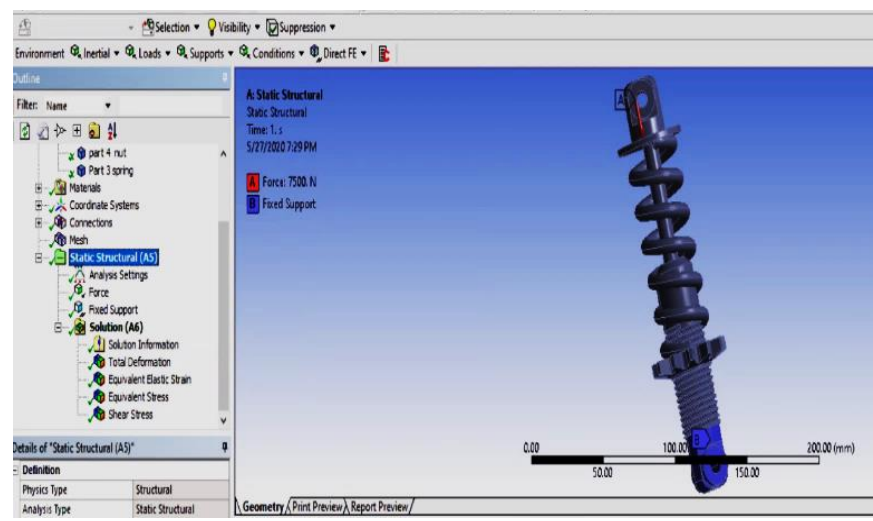

Figure 10. Boundary conditions applied for structural steel

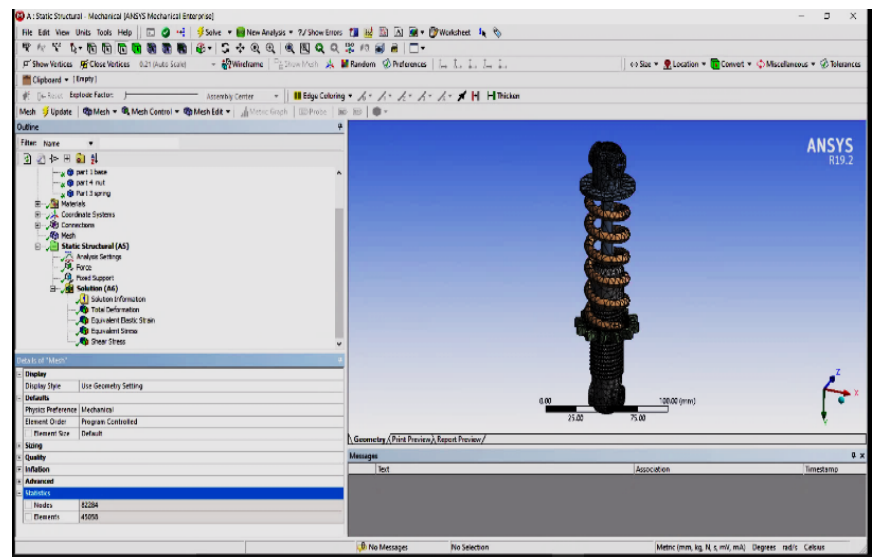

Figure 11. Boundary conditions applied for structural steel

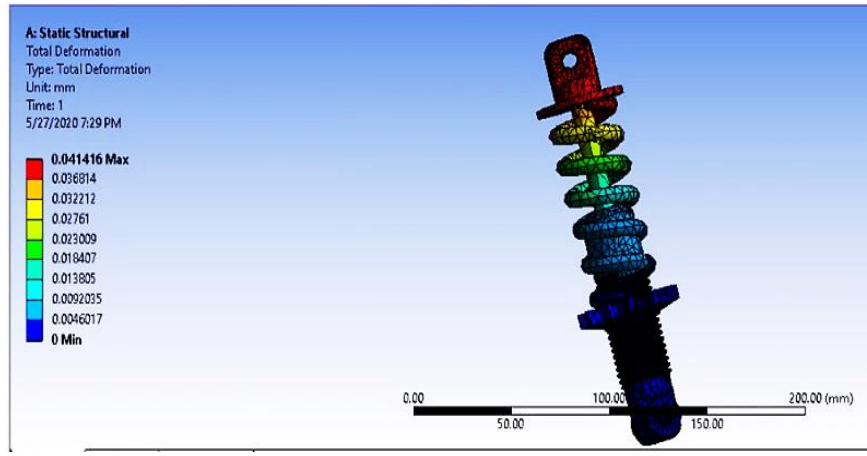

Figure 12. Total deformation for structural steel

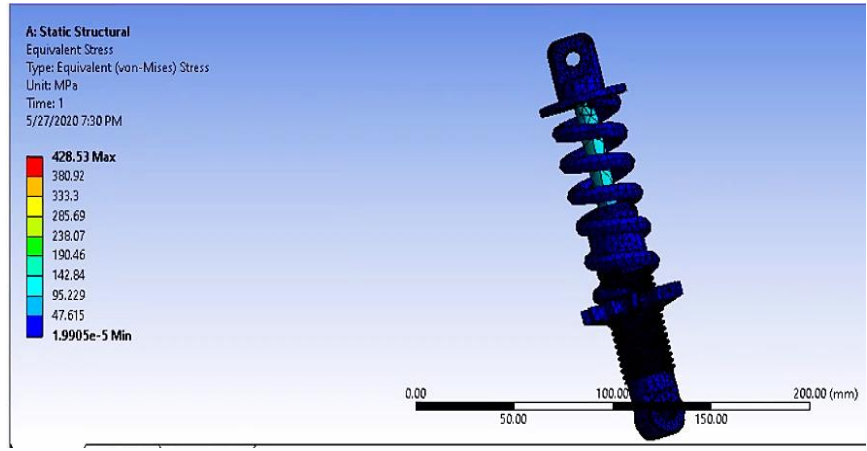

Figure 13. Stress of Structural steel

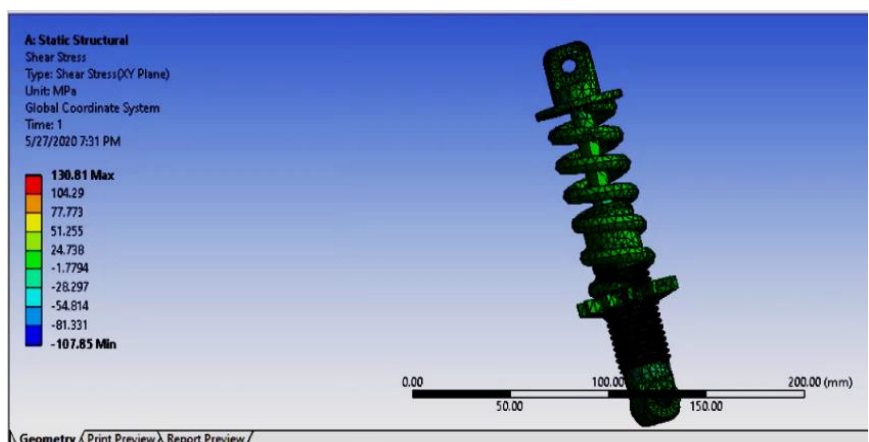

Figure 14. Shear stress for structural steel

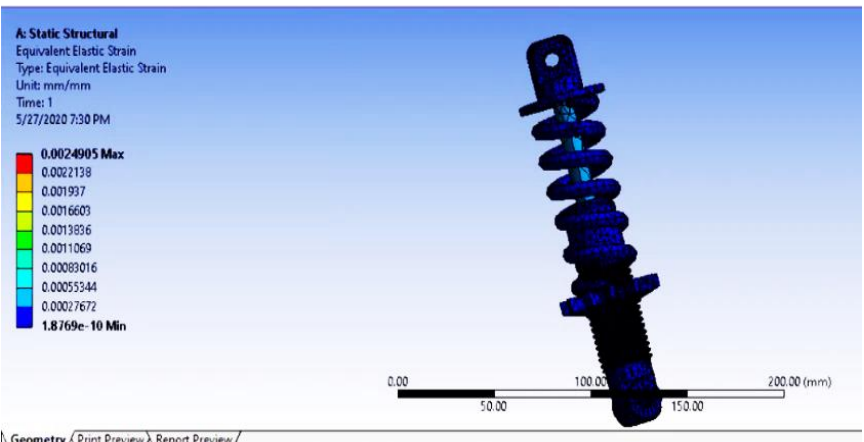

Figure 15. Elastic strain for structural steel

Table 9. Stress and stain values for structural steel

\begin{tabular}{cc}
\hline Nomenclature & Values \\
\hline Total deformation & $0.041416 \mathrm{~mm}$ \\
Stress & $428.53 \mathrm{MPa}$ \\
Shear stress & $130.81 \mathrm{MPa}$ \\
Elastic strain & 0.0024905 \\
\hline
\end{tabular}




\subsection{Structural analysis for E-Glass}

Figure 16 to Figure 19 shows the total deformation, stress, shear stress and elastic strain and the corresponding values of these stresses are shown in Table 10.

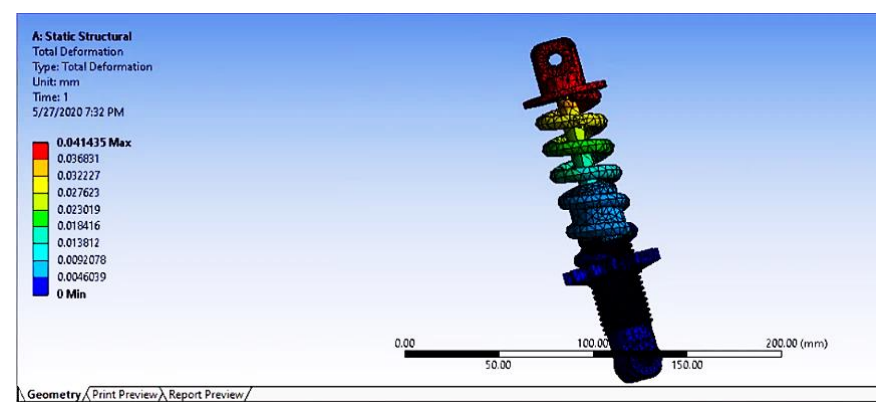

Figure 16. Total deformation for E-Glass

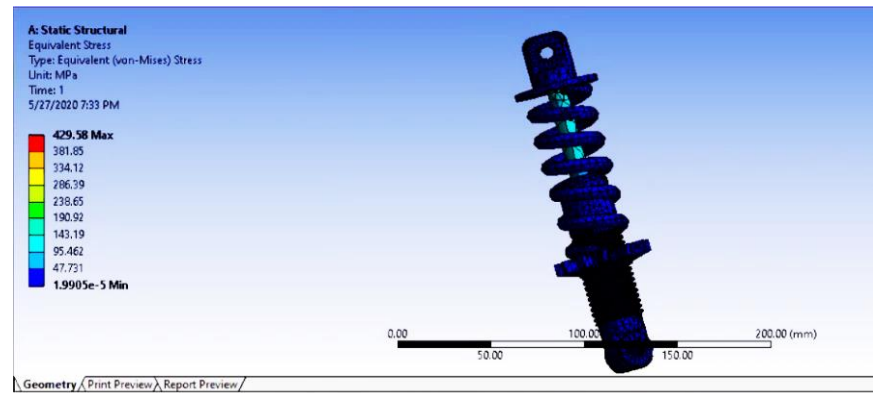

Figure 17. Stress of E-Glass

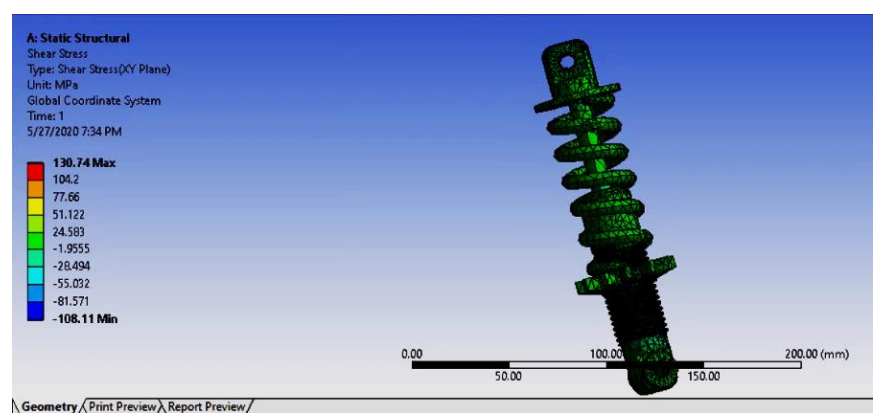

Figure 18. Shear stress of E-Glass

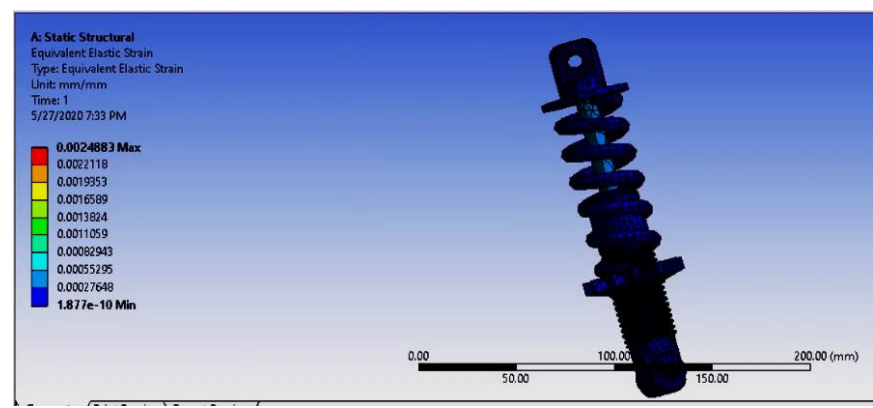

Figure 19. Elastic Strain on E-Glass

Table 10. Stress and stain values for E-Glass

\begin{tabular}{ll}
\hline Nomenclature & Values \\
\hline Total deformation & $0.041435 \mathrm{~mm}$ \\
Stress & $429.58 \mathrm{MPa}$ \\
Shear stress & $130.74 \mathrm{Mpa}$ \\
Elastic strain & 0.0024883 \\
\hline
\end{tabular}

\subsection{Structural analysis for carbon fiber}

Figure 20 to Figure 23 shows the total deformation, stress, shear stress and elastic strain for the carbon fiber and the corresponding values of these stresses are shown in Table 11.

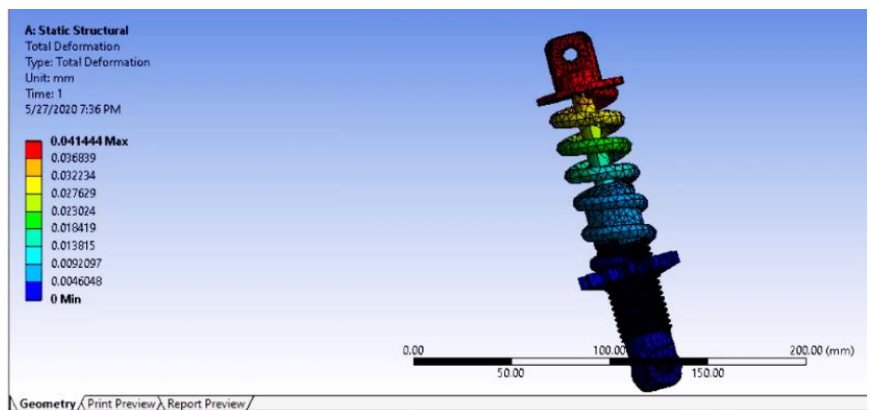

Figure 20. Total deformation for carbon fiber

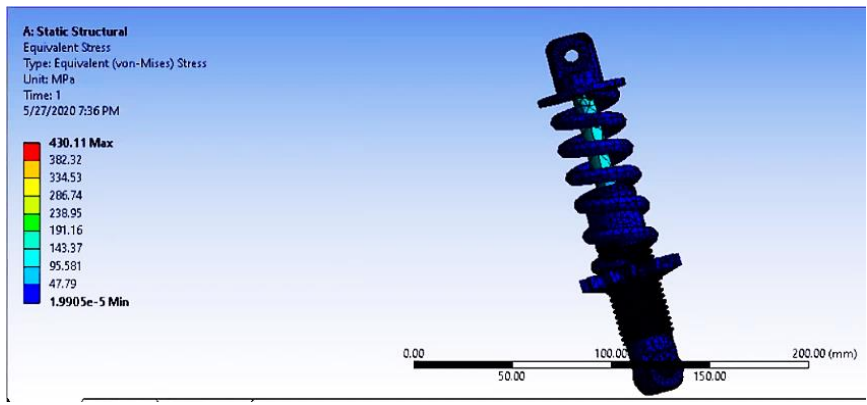

Figure 21. Stress of Carbon fiber

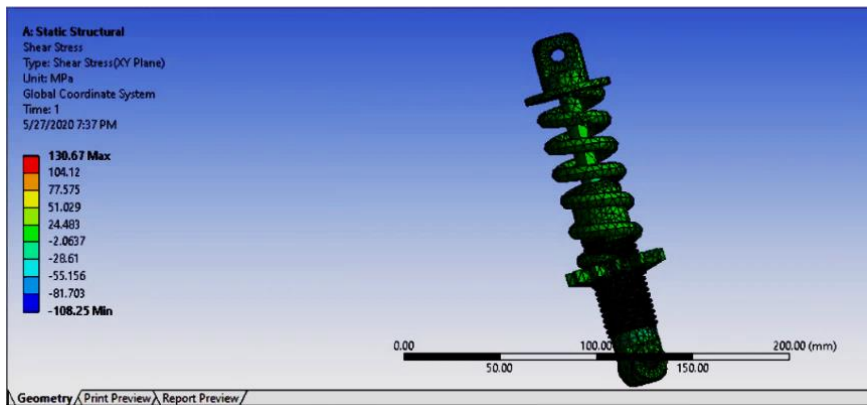

Figure 22. Shear stress of Carbon fiber

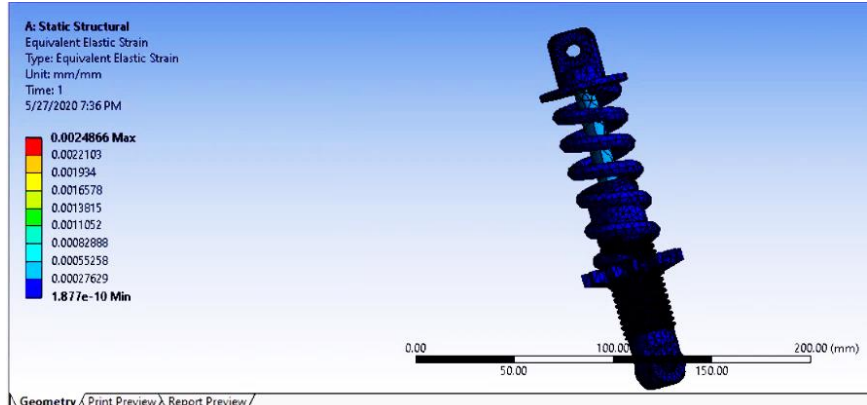

Figure 23. Elastic strain of Carbon fiber

Table 11. Stress and stain values for Carbon fiber

\begin{tabular}{cc}
\hline Nomenclature & Values \\
\hline Total deformation & $0.041444 \mathrm{~mm}$ \\
Stress & $430.11 \mathrm{MPa}$ \\
Shear stress & $130.67 \mathrm{MPa}$ \\
Elastic strain & 0.0024866 \\
\hline
\end{tabular}




\subsection{Structural analysis for coil spring with support for structural steel}

The structural analysis for coil spring with support for structural steel considering total deformation, stress, shear stress and elastic strain is as shown in Figure 24 to Figure 27.

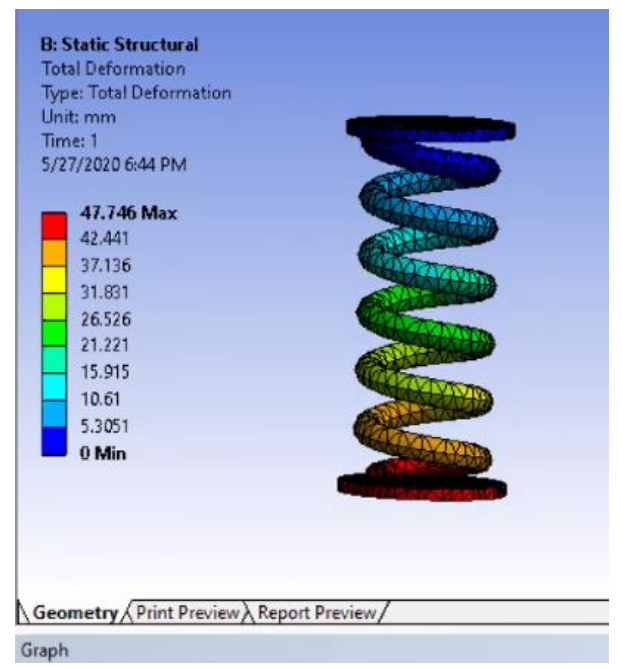

Figure 24. Total deformation for structural steel coil spring

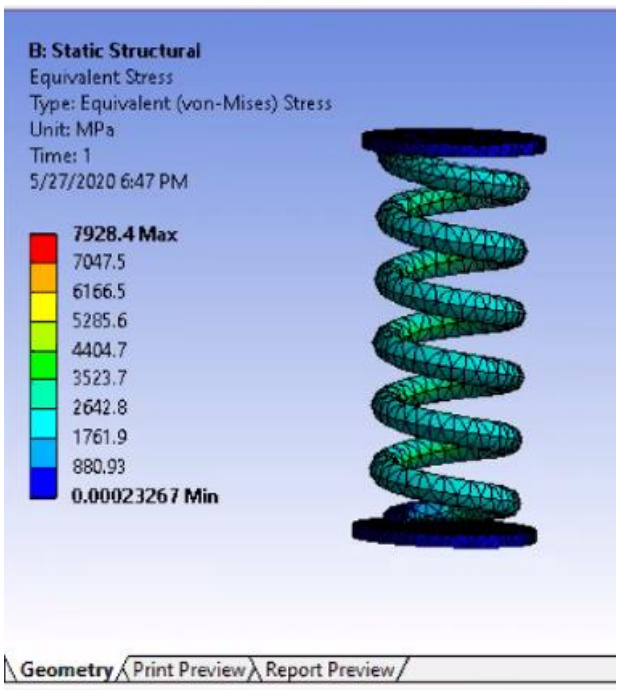

Figure 25. Stress of structural steel coil spring

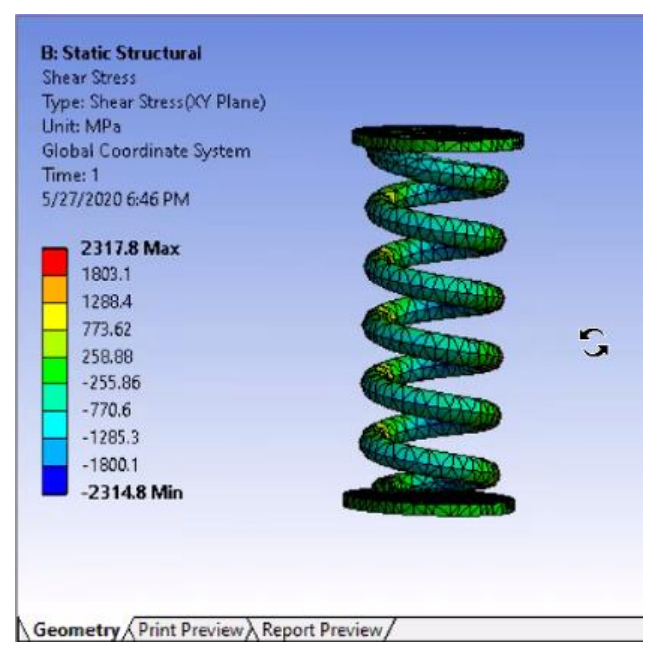

Figure 26. Shear stress of structural steel coil spring

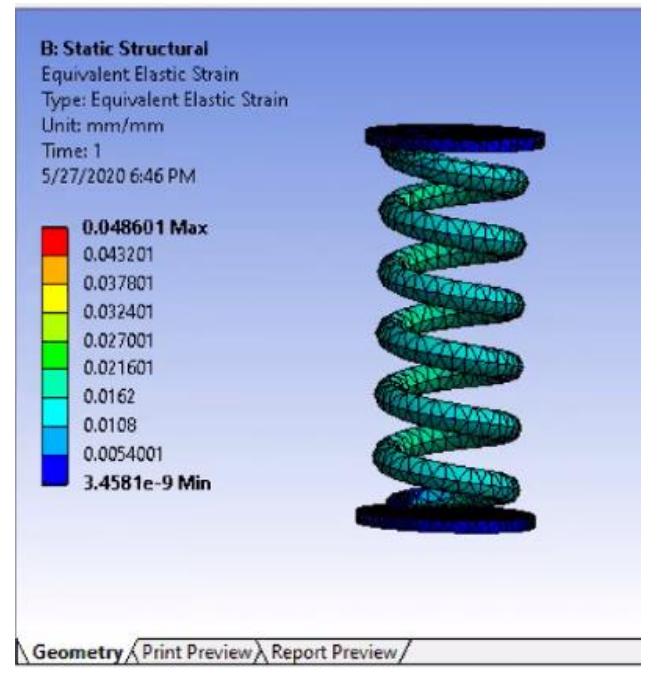

Figure 27. Elastic strain of structural steel coil spring

\subsection{Structural analysis for coil spring with support for E-} Glass

The structural analysis for coil spring with support for EGlass is as shown in Figure 28 to Figure 31.

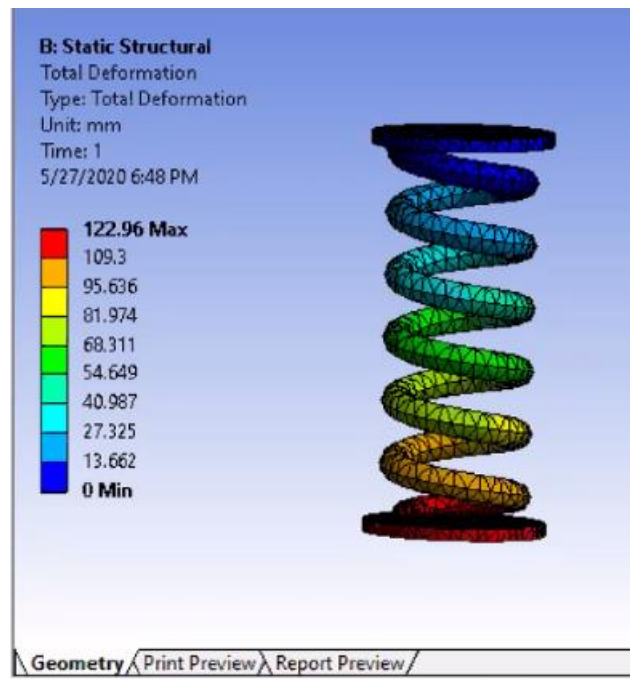

Figure 28. Total deformation for E-Glass coil spring

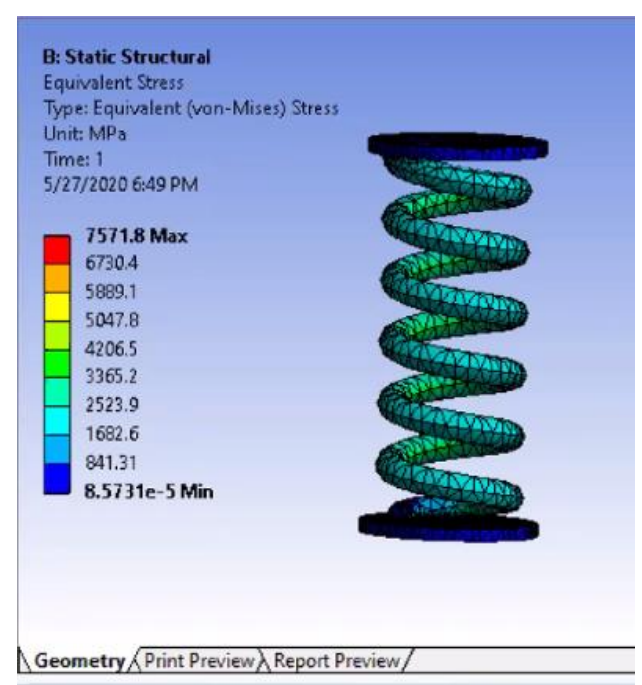

Figure 29. Stress for E-Glass coil spring 


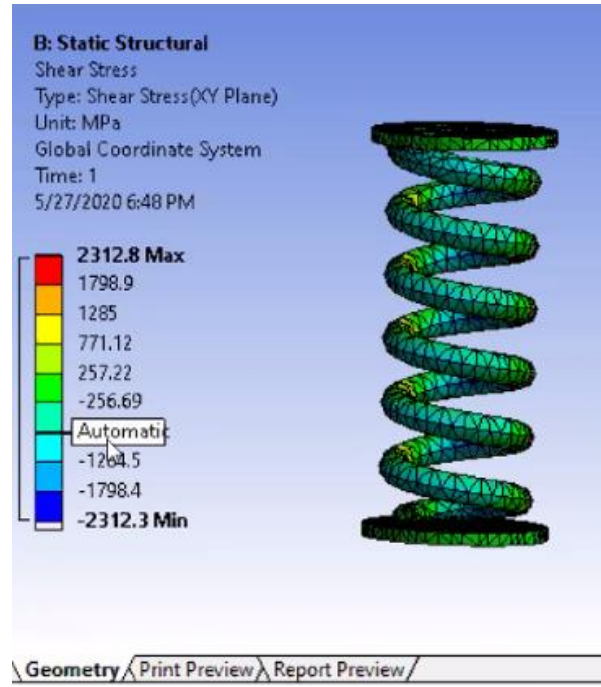

Figure 30. Shear stress of E-Glass coil spring

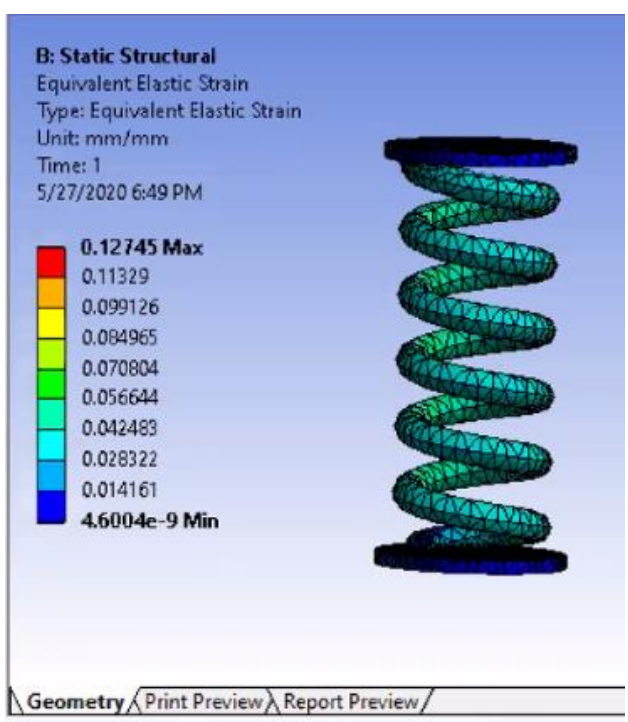

Figure 31. Elastic strain of E-Glass coil spring

\subsection{Structural analysis for coil spring with support for Carbon fiber}

The structural analysis for coil spring carbon fiber is as shown in Figure 32 to Figure 35.

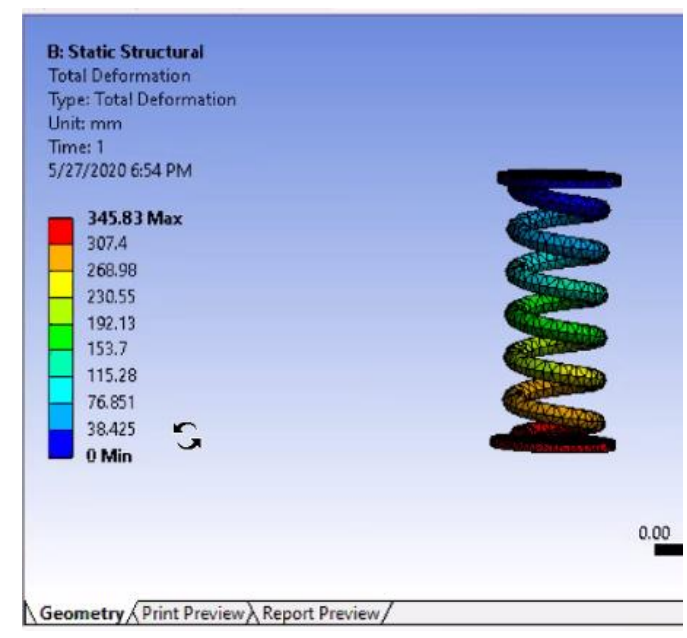

Figure 32. Total deformation of carbon fiber coil spring

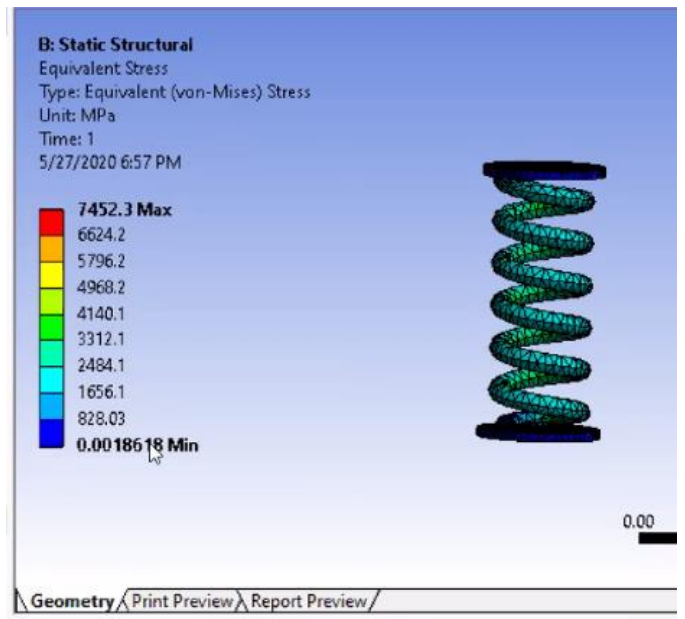

Figure 33. Stress of carbon fiber coil spring

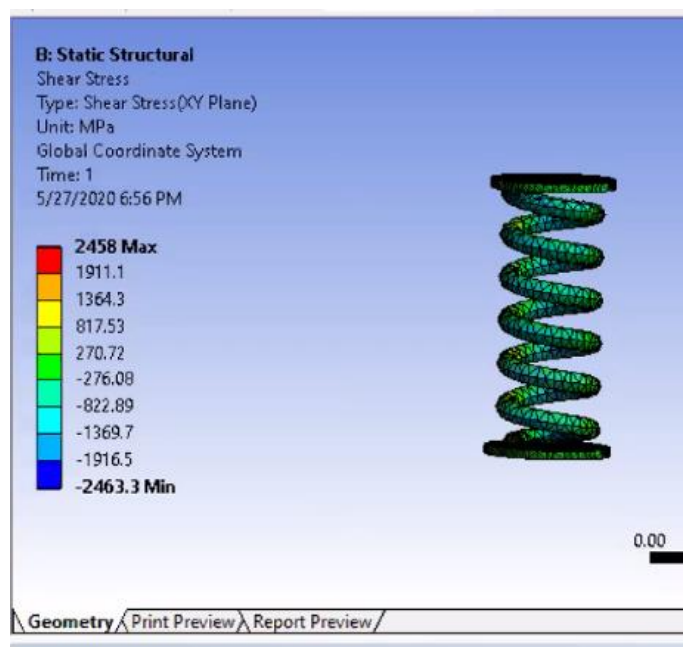

Figure 34. Shear stress of carbon fiber coil spring

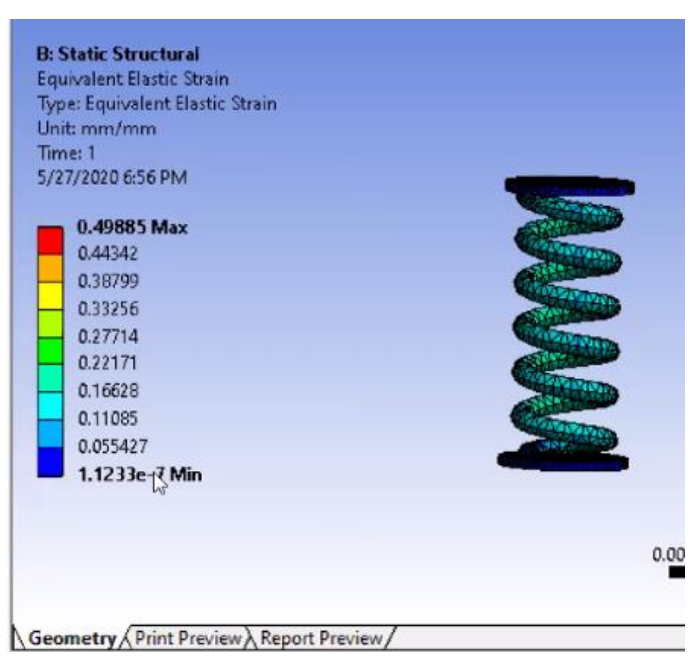

Figure 35. Elastic strain of carbon fiber coil spring

\subsection{Comparison of deformation for structural steel, carbon fiber and E-Glass coil spring}

Table 12 shows the comparison of deformation for structural steel, carbon fiber and E-Glass spring. From this comparison it is observed that the total theoretical deformation observed in case of steel material is $64.46 \mathrm{~mm}$ and the deformation observed using software is $47.74 \mathrm{~mm}$ and is much 
lesser as compared to theoretical values. But for carbon fiber, the deformation from analysis shows $345.83 \mathrm{~mm}$ whereas the deformation in case of theoretical values are higher which is $339.4 \mathrm{~mm}$. The type of behavior observed in case of E-Glass is just like the type of behavior observed in case of steel material.

Table 12. Theoretical and analytical comparison

\begin{tabular}{lll}
\hline Material & Theoretical Value & ANSYS value \\
\hline Steel & $64.46 \mathrm{~mm}$ & $47.74 \mathrm{~mm}$ \\
Carbon fiber & $339.4 \mathrm{~mm}$ & $345.83 \mathrm{~mm}$ \\
E-Glass & $168.57 \mathrm{~m}$ & $122.96 \quad \mathrm{~m}$ \\
\hline
\end{tabular}

\subsection{Comparison of deformation for structural steel, carbon fiber and E-Glass coil for suspension strut}

Figure 36 shows the comparison of deformation of structural steel, carbon fiber and E-Glass. From this figure it is observed that carbon fiber has the highest deformation of $0.041444 \mathrm{~mm}$ and structural steel has the lowest deformation of $0.041416 \mathrm{~mm}$.

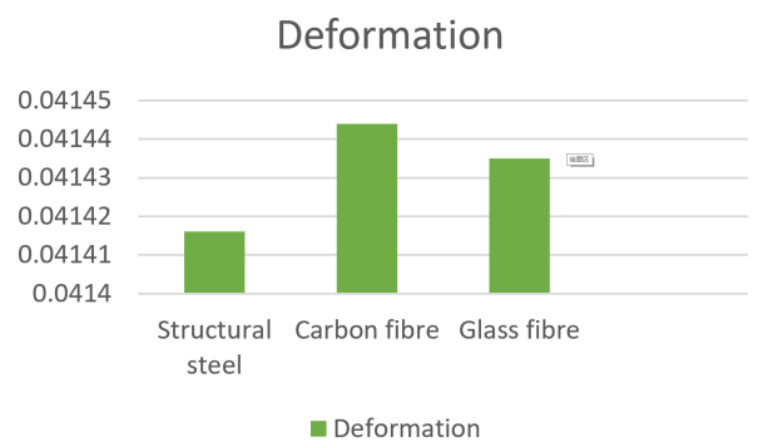

Figure 36. Comparison of deformation for various material

\subsection{Comparison of stress for structural steel, carbon fiber and E-Glass for suspension strut}

Figure 37 shows the comparison of structural steel, carbon fiber and E-Glass for suspension strut. From this graph it is observed that maximum stress is induced by carbon fiber which is $430.11 \mathrm{MPa}$ and stress induced by structural steel is the lowest at $428.53 \mathrm{MPa}$.

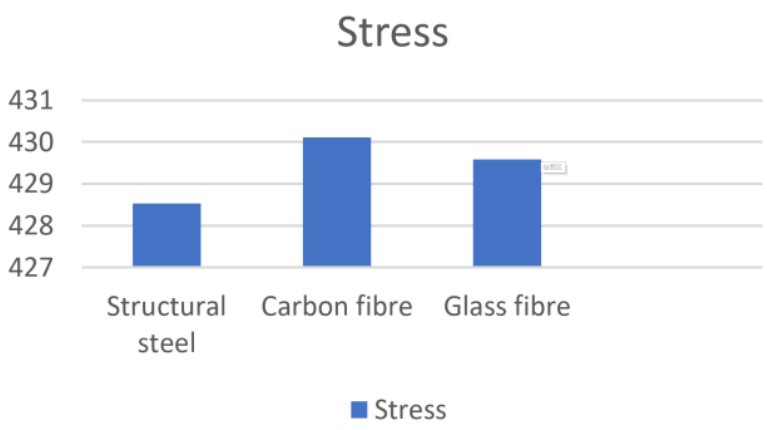

Figure 37. Comparison of stress for various material

3.9.1 Comparison of shear stress for structural steel, carbon fiber and E-Glass for suspension strut

Figure 38 shows the comparison of shear stress for structural steel, carbon fiber and E-Glass for suspension strut. From this figure it is observed that induced maximum shear is maximum for structural steel and is $130.81 \mathrm{MPa}$ and shear stress induced is the lowest in carbon fiber which is 130.67 $\mathrm{MPa}$.

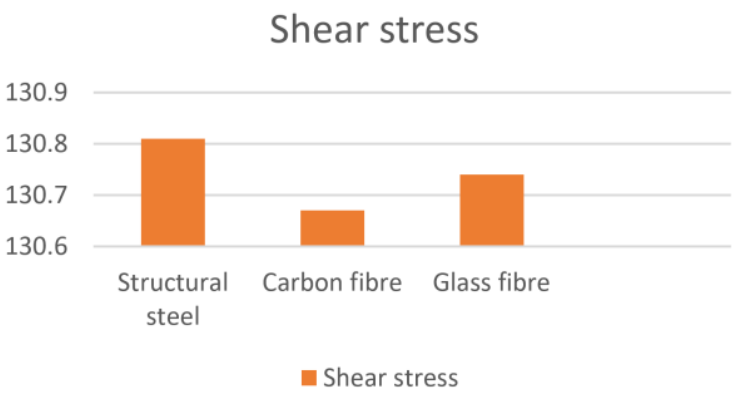

Figure 38. Comparison of shear stress for various material

3.9.2 Comparison of Elastic strain for structural steel, carbon fiber and E-Glass for suspension strut

Figure 39 shows the comparison of elastic strain for structural steel, carbon fiber and E-glass for suspension strut. From this figure it is observed that elastic strain is maximum for structural steel and is 0.0024905 and elastic strain is minimum in carbon fiber which is 0.0024866 . Also, it is observed that strain induced in glass fiber is closer to structural steel at 0.0024883 and it makes a good alternative to structural steel.

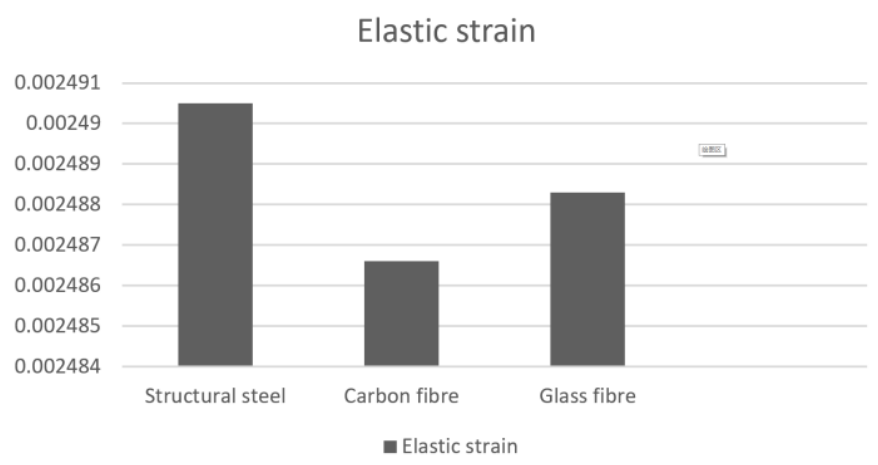

Figure 39. Comparison of Elastic strain for various material

\section{CONCLUSION}

Based on the results obtained from Ansys and the theoretical analysis done, it can be concluded that glass fiber is the best alternative material that can be used as a coil spring for the suspension strut and especially for high end vehicles due to the overall deformation and weight of the spring. It is also observed that glass fiber coil springs has a mass of $0.0626 \mathrm{~kg}$ which shows a $66.7021 \%$ lesser from steel coil springs which makes it more light weight which in turn gives better life expectancy. Apart from this, glass fiber is also abrasion resistant and less corrosive than steel. From the results it is also observed that elastic strain in case of glass fiber is 0.0024883 as compared to structural steel making it a suitable alternative. From the comparison of the theoretical value and analytical values it is shown the design is safe for glass fiber and falls under elastic limit.

\section{REFERENCES}

[1] Prakash, S., Babu, S.K., Prabhahar, M., Rasidh, C.K.M., Muhammadmarjan, S. (2017). Design and analysis of 
suspension strut using various material. Journal of Industrial Pollution Control, 33(2): 1754-1758.

[2] Lavanya, N., Rao, P.S., Reddy, M.P. (2014). Design and analysis of a suspension coil spring for automotive vehicle. International Journal of Engineering Research and Applications, 4(9): 151-157.

[3] Shinde, S.D., Maheshwari, S., Kumar, S. (2018). Literature review on analysis of various Components of McPherson suspension. Materials Today: Proceedings, 5(9): 19102-19108. https://doi.org/10.1016/j.matpr.2018.06.263

[4] Dodamani, S.S., Suresh, C., Nagaraj, D. (2016). Design and Fatigue Analysis of McPherson Strut Assembly Coil Spring. Dept. of Machine Design, BIT, Bangalore, India.

[5] Alsahlani, A., Khashan, M.K., Khaleel, H.H. (2018). Design and analysis of coil spring in vehicles using finite elements method. Int. J. Mech. Product. Eng. Res. Dev., 8(4):

615-624. https://doi.org/10.24247/ijmperdaug201864

[6] Vaidya, G., Kanoje, P., Tidke, N. (2017). Advancement in suspension system for automobile industry: A review. International Journal of Engineering Technology Science and Research, 4(9): 549-552.

[7] Pawar, H.B., Patil, A.R., Zope, S.B. (2016). Design and analysis of a front suspension coil spring for three wheeler vehicle. International Journal of Innovations in Engineering Research and Technology, 3(2): 1-6.

[8] Vijayeshwar, B.V., Preetham, B.M., Bhaskar, U. (2017). Design and static analysis of helical suspension spring with different materials. International Advanced Research Journal in Science, Engineering and Technology, $4:$ 94-98. https://doi.org/10.17148/IARJSET

[9] Pankaj, S., Rushikesh, A., Sanket, W., Viraj, J., Kaushal, P. (2017). Design and analysis of helical compression spring used in suspension system by finite element analysis method. International Research Journal of Engineering and Technology (IRJET), 4(4): 1-11.
[10] Konieczny, Ł., Burdzik, R. (2017). Modern suspension systems for automotive vehicles and their test methods. Vibroengineering PROCEDIA, 14: 233-237. https://doi.org/10.21595/vp.2017.19238

[11] Purushotham, A. (2013). Comparative simulation studies on MacPherson suspension system. International Journal of Modern Engineering Research (IJMER), 3(3): 13771381.

[12] Ali, T., Bakar, R.A., Meng, G.L., Jafar, Z.A. (2017). Investigation of passenger car using Macpherson strut for suspension system pt. 1: Vehicle behaviour variation of time response. In MATEC Web of Conferences, 90: 01072. https://doi.org/10.1051/matecconf/20179001072

[13] Jain, A., Misra, S., Jindal, A., Lakhian, P. (2017). Structural analysis of compression helical spring used in suspension system. In AIP Conference Proceedings, 1859(1): 020080. https://doi.org/10.1063/1.4990233

[14] Yadav, A.K., Kanaujiya, S.P., kumar, M., Kumar, V., Bhaskar, A. (2017). Analysis of helical spring of twowheeler suspension system using Ansys workbench 16.2. International Journal for Research in Applied Science \& Engineering Technology (IJRASET), 5(5): 1257-1278.

[15] Bhaskar, U., Guruchethan, A.M., Devendra, Reddy, M., (2016). Performance analysis of fiber reinforced composite spring Embedded with steel wire. International Journal of Engineering Research and General Science, 4(2): 757-763.

[16] Krishnamoorthy, A., Karthik, R. (2015). Study of composite helical spring using glass fibre with araldite LY556 and XY54. In Applied Mechanics and Materials, 766-767:

523-527. https://doi.org/10.4028/www.scientific.net/AMM.766767.523

[17] Manjunatha, T.S., Budan, D.A. (2012). Manufacturing and experimentation of composite helical springs for Automotive suspension. International Journal of Mechanical Engineering and Robotics Research, 1(2): 229-241. 